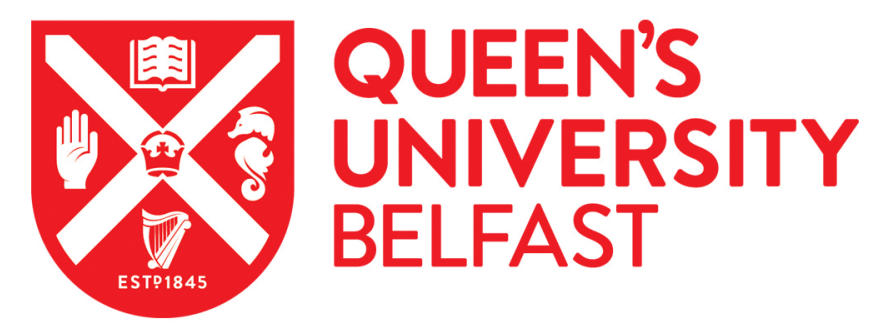

\title{
Seismic damage detection for a steel braced frame structure
}

McCrum, D. P., \& Staino, A. (2015). Seismic damage detection for a steel braced frame structure. Proceedings of the ICE - Structures and Buildings, 168(9), 636-648. https://doi.org/10.1680/stbu.14.00034

Published in:

Proceedings of the ICE - Structures and Buildings

Document Version:

Publisher's PDF, also known as Version of record

Queen's University Belfast - Research Portal:

Link to publication record in Queen's University Belfast Research Portal

Publisher rights

(C) 2015 ICE Publishing

Permission is granted by ICE Publishing to print one copy for personal use. Any other use of these PDF files is subject to reprint fees.

\section{General rights}

Copyright for the publications made accessible via the Queen's University Belfast Research Portal is retained by the author(s) and / or other copyright owners and it is a condition of accessing these publications that users recognise and abide by the legal requirements associated with these rights.

Take down policy

The Research Portal is Queen's institutional repository that provides access to Queen's research output. Every effort has been made to ensure that content in the Research Portal does not infringe any person's rights, or applicable UK laws. If you discover content in the Research Portal that you believe breaches copyright or violates any law, please contact openaccess@qub.ac.uk. 


\section{Seismic damage detection for a steel braced frame structure}

Daniel P. McCrum BA, BAI, MSc, PGrad Dip Stats, PhD, CEng, MIEl Lecturer in Structural Engineering, School of Planning, Architecture and Civil Engineering, Queen's University Belfast, UK
Andrea Staino BSC, MSc, PhD

Post-Doctoral Research Associate, Department of Civil, Structural \& Environmental Engineering, Trinity College Dublin, Dublin, Ireland

A new approach for global detection of seismic damage in a single-storey steel concentrically braced frame (CBF) structure is presented. The filtered lateral in-plane acceleration response of the CBF structure is integrated twice to provide the lateral in-plane displacement that is used to infer buckling and yielding damage. The level of interstorey drift of the CBF during a seismic excitation allows the yield and buckling of the bracing members to be identified and indirectly detects damage based on exceedance of calculated lateral in-plane displacement limits. A band-pass filter removes noise from the acceleration signal followed by baseline correction being used to reduce the drift in velocity and displacement during numerical integration. This pre-processing results in reliable numerical integration of the frame acceleration that predicts the displacement response accurately when compared to the measured lateral displacement of the CBF structure. Importantly, the structural damage is not assumed through removal of bracing members, rather damage is induced through actual seismic loading. The buckling and yielding displacement threshold limits used to identify damage are demonstrated to identify accurately the initiation of buckling and yielding.

\section{Notation}

$a_{\mathrm{g}} \quad$ peak ground acceleration

A cross-sectional area of the section

$b \quad$ width of the section

$E \quad$ Young's modulus of the structural steel

$F_{\mathrm{c}} \quad$ brace member compression force

$F_{\mathrm{t}} \quad$ brace member tension force

$G \quad$ torsional modulus

$I$ second moment of area of the section

$I_{\mathrm{y}} \quad$ minor axis second moment of area of the section

$I_{\mathrm{z}} \quad$ major axis second moment of area of the section

$K \quad$ lateral in-plane frame stiffness

$L_{\mathrm{cr}} \quad$ effective length of a compression member

$N_{\text {cr }} \quad$ Euler buckling capacity of a brace member

$P \quad$ lateral in-plane frame force

$r_{y} \quad$ radius of gyration about the weak axis

$t \quad$ thickness

$\delta \quad$ lateral in-plane frame deflection

$\theta$ angle of inclination of the bracing to the horizontal axis

$\bar{\lambda} \quad$ bracing member's non-dimensional slenderness

\section{Introduction}

Seismic damage detection in building structures enables engineers to assess the safety and allowable occupancy of a building during/after an earthquake event. Seismic damage detection can be categorised as pre and post-damage methods (mostly performed offline) or structural health monitoring (SHM) methods (online). The detection methods can then be further categorised as global (detect storey location of damage) or local (detect location of damage in individual structural members). This paper presents an offline global damage detection strategy for a steel concentrically braced frame (CBF) structure.
In steel CBF structures the buckling of the bracing members is typically visually detectable after a moderate seismic event; however, it may not be obvious if the bracing has yielded, and to what extent. If buckling alone exists, the frame may have adequate capacity for moderate aftershocks/wind loading as long as the residual interstorey drift is sufficiently low. If bracing members had buckled but not yielded during a seismic event, the structure could be deemed to be safe to be occupied until repair or replacement could be performed. Therefore, it is important to know if buckling and/or yielding are present in the bracing members. The majority of previous damage detection research in steel CBF structures assumes damage in bracing members through removal of members. This assumes that the bracing member has fractured. Such an assumption ignores structural response up to fracture. However, many damage scenarios in small to moderate earthquakes exist where the bracing members do not fracture but either buckle and do not yield, or buckle and yield. In this paper, damage is induced through seismic excitation of the structure.

Global methods of damage detection that track model parameters such as mode shapes (Hearn and Testa, 1989; Yao et al., 1992) interstorey drift (Skolnik and Wallace, 2010), storey stiffness (Koh et al., 1992), finite-element model updating techniques ( $\mathrm{Wu}$ and $\mathrm{Li}, 2006$ ) and purely statistical approaches (Krishnan Nair et al., 2006) have been shown to be successful, if sometimes problematic. The most common global method of damage detection is interstorey drift tracking because the double integration of readily available acceleration data can be performed. Such vibration-based methods are typically based on the principle that damage will cause detectable changes in the modal properties of the structure. 
Changes in physical properties such as mass, stiffness or damping will result in detectable changes in modal properties such as frequency, mode shapes or modal damping (Fan and Qiao, 2011). Extensive literature reviews on vibration-based methods have been written by Doebling et al. (1996), Sohn et al. (2003) and Carden and Fanning (2004).

Many researchers (Ching and Beck, 2004; Johnson et al., 2004; Kharrazi et al., 2002; Mikami et al., 2007) have investigated methods of SHM/damage diagnosis for the scaled fourstorey, two-by-two bay, steel braced frame ASCE structural health monitoring task group benchmark damage structure (IASC-ASCE, 1999). Varying levels of damage scenarios were tested, with damage consisting of removal of single or multiple brace members. Kharrazi et al. (2002) studied the output-only vibration from the tests using finite-element model updating to identify global damage through changes in modal properties. Ching and Beck (2004) used pre and post-damage modal parameters based on Bayesian model updating to identify damage through hammer or ambient vibrations. The method was successful for member damage but less successful for connection damage. Mikami et al. (2007) tested blind excitation using a power spectral density data technique to identify a greater number of modes with the potential of improving the accuracy of detection. Hera and Hou (2004) investigated a non-modal-based method of damage detection using wavelets.

Aside from the IASC-ASCE benchmark structure, others have also investigated damage detection in steel braced frame structures. Morita et al. (2001) investigated damage in a scaled fivestorey steel braced frame structure through variation of modal parameters pre and post-damage. Damage included loosening bolts, removal of brace members and cutting parts of beams. Sometimes their methods were successful at globally locating the storey damage, others not. Xiadong et al. (2007) simulated damage through removal of braces in a scaled two-storey steel braced frame structure. Mode shapes of the undamaged structure were modelled using finite-element models while the damage index method and damage locating vectors method were used to identify localised damage and severity. Sabatino and Ervin (2012) used the natural frequencies and mode shapes of an idealised steel/aluminium braced frame structure with/without damage to assess the effectiveness of different detection parameters. The baseline undamaged frequencies and mode shapes were compared to the structure with brace members removed (damaged). Six unique damage indicators were used to assess damage based on change in modal properties.

This paper describes a new practical strategy to assess initiation of global damage in a single-storey steel CBF structure using a single relative lateral in-plane acceleration signal. The acceleration signal is filtered and integrated twice to provide a reliable predicted lateral in-plane displacement response. Lateral in-plane displacement thresholds based on calculated buckling and yielding displacement limits are then used to identify the initiation of buckling and yielding in the $\mathrm{CBF}$ structure. Test results of measured displacement and strains are compared to displacement limits and demonstrate the accuracy and applicability of the strategy. Importantly, damage is not initiated through removal of bracing members, but through actual seismic loading. The strategy proposed here does not rely on detectable changes in response; rather it measures the level of interstorey drift to infer damage. The offline procedure demonstrated has been shown to be successful and could, with a change to the filtering processes (e.g. use of a Kalman filter (Kalman, 1960)), potentially be implemented in an online procedure to detect damage globally.

\section{Braced frame details}

The structural frame investigated in this paper was designed as part of a larger three-storey CBF structure to resist an earthquake with a peak ground acceleration, $a_{\mathrm{g}}=3 \cdot 5 \mathrm{~m} / \mathrm{s}^{2}$. The structure was designed using the lateral pushover method of analysis in BS EN 1998-1:2004 (CEN, 2004). The test frame comprises a ground-storey frame from the larger structure and comprises a $356 \times 140 \times 36 \mathrm{~mm}$ universal beam (UB) beam and two $203 \times$ $203 \times 46 \mathrm{~mm}$ universal column (UC) columns (as per Figure 1). Two sets of tests were conducted with bracing tested as follows; $30 \times 30 \times 3 \mathrm{~mm}$ square hollow section (SHS) with normalised slenderness, $\bar{\lambda}=1.68$ or $50 \times 30 \times 3 \mathrm{~mm}$ rectangular hollow section (RHS) with $\bar{\lambda}=1 \cdot 57$. The section properties of the bracing members are shown in Table 1. The brace sizes are within the BS EN 1993-1-1:2005 (CEN, 2005) normalised slenderness limits of $1 \cdot 3<\bar{\lambda} \leq 2 \cdot 0$. The steel properties are $f_{\mathrm{y}}=235 \mathrm{~N} / \mathrm{mm}^{2}$, $E=210000 \mathrm{~N} / \mathrm{mm}^{2}$ and $G=150000 \mathrm{~N} / \mathrm{mm}^{2}$. The $203 \times$ $203 \times 46 \mathrm{~mm}$ UC stub column sections located at the support and beam-column connections were used to replicate pinned connections. A series of displacement controlled seismic tests was performed that is described in more detail in the next section. The strain gauges are located on the front and top face of the bracing sections at locations of suspected buckling as shown in Figure 1. Strain gauge (SG) 4 is located on the front face of the brace section and SG 5 is located on the top face of the brace section. SG 4 and 5, SG 6 and 7, SG 8 and 9 and SG 10 and 11 are located on the front and side of the bracing members at the

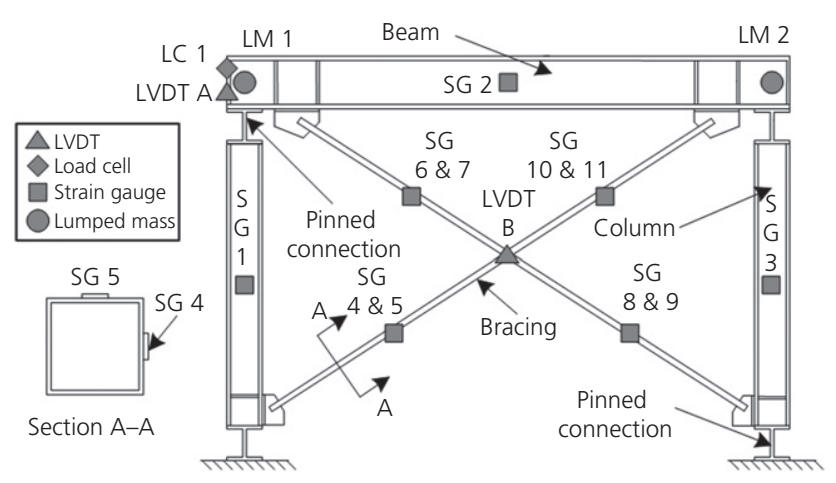

Figure 1. Steel concentrically braced test frame with idealised pinned connections and test instrumentation details 


\begin{tabular}{lcccccccc}
\hline Section dimensions: $\mathrm{mm}$ & $t: \mathrm{mm}$ & $A: \mathrm{cm}^{2}$ & $b / t$ & $d / t$ & $l_{z}: \mathrm{cm}^{4}$ & $l_{y}: \mathrm{mm}^{4}$ & $r_{y}: \mathrm{cm}$ & $\lambda$ \\
\hline $30 \times 30$ & 3 & 3.01 & 8 & 8 & 3.5 & 3.5 & 1.08 & 1.68 \\
$50 \times 30$ & 3 & 4.34 & 8 & 14.7 & 13.6 & 5.94 & 1.16 & 1.57
\end{tabular}

Table 1. Hot-rolled steel bracing cross-sectional properties

expected location of plastic hinge formation. These strain gauges are located to record the maximum strain in the bracing members. The location of the displacement sensors (linear variable differential transformer (LVDT) 1 and LVDT 2), load cell (LC 1) and numerically modelled lumped masses (LM 1 and LM 2) can also be seen in Figure 1. LVDT A measures the inplane lateral frame displacement and is located internally in the actuator. LVDT B is an external LVDT and measures the out-ofplane brace displacement at the crossing of the bracing members as shown in Figure 1. SG 1 and SG 3 measure the axial strain in the columns, whereas SG 2 measures the axial strain in the beam.

In order to provide context, the structural behaviour of a pinended single brace member subjected to low cycle loading, during one load cycle is briefly described herein. Initially when a brace member is loaded in compression, the member axially shortens and deflects out of plane at mid-span as a result of initial imperfections. When the maximum compressive load is reached, the brace buckles and continues to deflect out of plane at mid-span to accommodate increased axial displacement. A plastic hinge forms at mid-span, leading to reduced axial load capacity. On load reversal to tension loading, elastic recovery occurs and the brace straightens. The unloaded branch from compression to tension has a lower stiffness than the initial compression loading phase owing to the presence of residual displacements. Tensile yielding then occurs when the loading continues past yield and the brace has straightened. Elastic unloading then occurs when the load reverses to compression. Buckling of the brace will then occur at a reduced load below the maximum compression load owing to the residual deflections in the brace member.

\section{Test procedure}

The hybrid test method adopted in this paper is a dynamic testing method that combines physical testing and simultaneous numerical modelling (McCrum and Broderick, 2013a, 2013b). A hybrid test was performed with the masses numerically modelled and the CBF physically tested (essentially a pseudo-dynamic test (refer to Shing and Mahin, 1984). The single-storey CBF structure was supported off a reaction frame as shown in Figure 2, and therefore the measured displacements and thus accelerations are absolute frame accelerations. The test frame is located between two side-by-side reaction frames. The actuator applies the command displacement to the frame as shown in Figure 2. The lumped masses were numerically modelled at the ends of the beams (refer to Figure 1).
The inertial displacement resulting from the excitation was applied to the structure in a displacement controlled test using closed-looped proportional integral derivative control. The MTS actuator has a $150 \mathrm{kN}$ capacity with a stroke of $\pm 125 \mathrm{~mm}$. An internally mounted displacement sensor provides the actuator displacement and an internal load cell provides the force feedback. Tests are performed at an expanded timescale, with the acceleration and velocity numerically calculated from the equation of motion using the measured force and displacement from each time step of the time history. At the first time step, the target displacement of the test frame resulting from the earthquake ground motion is calculated from the equation of motion. The first time step target displacement is purely numerically calculated. The target displacement is applied by the actuator and the resulting force and displacement are measured at the end of the time step. In the second time step, the resulting force and displacement that have been measured by the actuator load cell (LC 1) and displacement sensor (LVDT A), respectively, at the end of the first time step are then input into the equation of motion as a physically measured force and displacement. The third time step uses the displacement and force measured from the end of the second time step to calculate the next target displacement. The procedure continues until the end of the earthquake record. Each time step is $0 \cdot 01 \mathrm{~s}$. The test

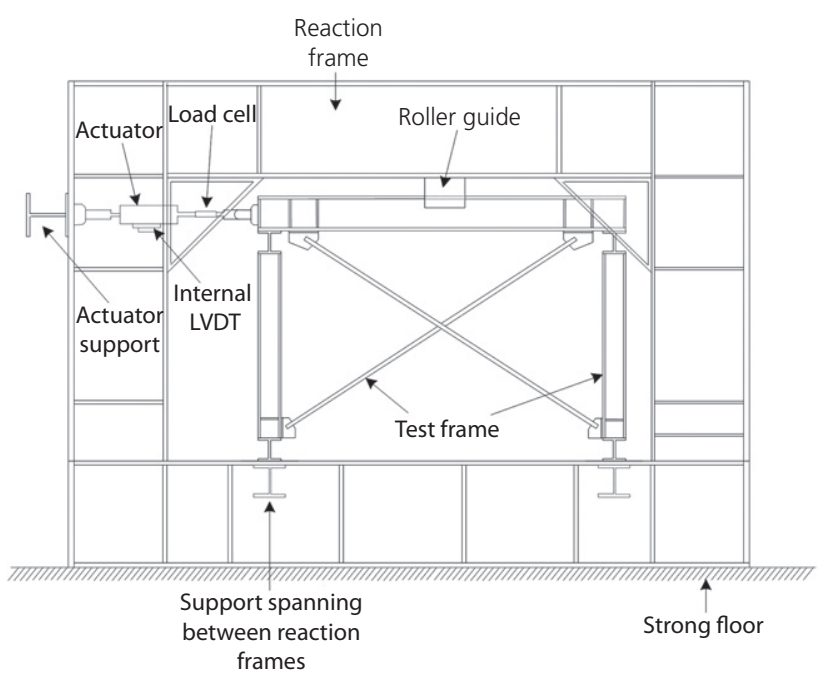

Figure 2. Experimental set-up showing side-by-side reaction frames with braced frame and actuator inset in between reaction frames 
runs for approximately $700 \mathrm{~s}$ in actual time, which equates to $40 \mathrm{~s}$ of the input earthquake record. The test is referred to as a pseudo-dynamic test because it does not occur in real time.

The Taiwan (1986) earthquake time history scaled to $0 \cdot 4,1 \cdot 0$ and $2 \cdot 0$ was used as the input ground acceleration as shown in Table 2. The Taiwan earthquake had a magnitude of $7 \cdot 3$, was recorded a distance of $39 \mathrm{~km}$ from its epicentre and had a peak ground acceleration (PGA) of $0 \cdot 153 \mathrm{~g}$. Two different numerically modelled masses were applied to the braced frame as shown in Table 2 . The $50 \times 30 \times 3 \mathrm{~mm}$ RHS frame has a larger seismic demand due to the increased lumped masses. P-delta tests at low amplitude elastic displacements were performed to obtain lateral in-plane frame stiffnesses as shown in Table 2. Tests 1 to 3 used the same bracing specimen during all tests and likewise tests 4 to 6 used the same bracing specimen during all tests. The re-use of the test frame in subsequent tests is evident as the stiffness softens slightly after each test, as shown in Table 2.

\section{Damage detection strategy}

The proposed damage detection strategy consists of three parts: (a) filtering and baseline correction of acceleration response and then double numerical integration of the corrected signal to give the predicted displacement; $(b)$ identification of buckling by checking the predicted displacement against buckling displacement threshold limits; and (c) identification of tension yielding by checking the predicted displacement against yield displacement threshold limits.

The brace members have been designed according to BS EN 1998-1:2004 (CEN, 2004) and are designed to resist seismic loading through tension only; however, in practice compressive resistance exists. The low cycle fatigue and residual deformations in the bracing result in reduced buckling capacity of the bracing during multiple compression loading cycles. Also, tension yielding in the bracing results in yielding occurring at a reduced stress in subsequent load cycles, thus reducing the tension carrying capacity of the bracing member in subsequent load cycles. As the structure has been designed to resist lateral loading through tension only the yielding identification is

\begin{tabular}{llcccr}
\hline $\begin{array}{l}\text { Test } \\
\text { no. }\end{array}$ & $\begin{array}{l}\text { Test } \\
\text { type }\end{array}$ & $\begin{array}{c}\text { Scaling } \\
\text { factor }\end{array}$ & $\begin{array}{c}\text { Brace } \\
\text { size: } \mathrm{mm}\end{array}$ & $\begin{array}{c}\text { Nodal } \\
\text { masses: kg }\end{array}$ & $\begin{array}{r}\text { Stiffness: } \\
\mathrm{N} / \mathrm{mm}^{2}\end{array}$ \\
\hline 1 & Elastic & 0.4 & $30 \times 30 \times 3$ & 45634 & 9805 \\
2 & Inelastic & 1.0 & $30 \times 30 \times 3$ & 45634 & 9846 \\
3 & Inelastic & $2 \cdot 0$ & $30 \times 30 \times 3$ & 45634 & 9379 \\
4 & Elastic & 0.4 & $50 \times 30 \times 3$ & 46924 & 11408 \\
5 & Inelastic & 1.0 & $50 \times 30 \times 3$ & 46924 & 11157 \\
6 & Inelastic & 2.0 & $50 \times 30 \times 3$ & 46924 & 10733
\end{tabular}

Table 2. Experimental programme and details more important than the buckling identification in terms of damage detection of the $\mathrm{CBF}$ structure.

\subsection{Procedure}

The methodology of the damage detection strategy is outlined as follows.

(a) Filter recorded acceleration signal using a band-pass filter to remove noise from the relevant frequency band of interest.

(b) Perform a polynomial baseline correction on the acceleration signal and numerically integrate the corrected acceleration twice to yield the predicted displacement.

(c) Compare predicted displacement with measured test displacement and ensure within acceptable error bounds.

(d) Calculate the buckling displacement and compare to predicted displacement to identify buckling. The Euler buckling capacity, $N_{\text {cr }}$ is calculated from

$$
\text { 1. } N_{\mathrm{cr}}=\pi^{2} E I / L_{\mathrm{cr}}^{2}
$$

where $E$ is the Young's modulus, $I$ is the second moment of area of the section and $L_{\mathrm{cr}}$ is the effective length of the compression member. The brace member end connections are assumed as pinned-pinned. $N_{\mathrm{cr}}=37 \cdot 4 \mathrm{kN}$ for $30 \times 30 \times 3 \mathrm{~mm}$ SHS and $N_{\text {cr }}=41.61 \mathrm{kN}$ for $50 \times 30 \times$ $3 \mathrm{~mm}$ RHS. These forces correspond to a lateral frame displacement calculated as follows.

(i) The tension force in the tension bracing member, $F_{\mathrm{t}}$ and compression force in the compression bracing member, $F_{\mathrm{c}}$ are assumed to be equal up until buckling that is $F_{\mathrm{c}}=F_{\mathrm{t}}$. Therefore, the lateral frame force, $P$ (actuator force) corresponding to yield is equal to

$$
\text { 2. } P=\left(F_{\mathrm{c}}+F_{\mathrm{t}}\right) \cos \theta
$$

as $F_{\mathrm{c}}=F_{\mathrm{t}}$

3. $P=\left(N_{\mathrm{cr}}+N_{\mathrm{cr}}\right) \cos \theta=2 N_{\mathrm{cr}} \cos \theta$

where $\theta$ is the angle of inclination of the bracing to the horizontal axis.

(ii) Using Equation 3, the lateral frame force is $P=41.47 \mathrm{kN}$ for the $30 \times 30 \times 3 \mathrm{~mm}$ SHS frame and $P=66.46 \mathrm{kN}$ for the $50 \times 30 \times 3 \mathrm{~mm}$ RHS frame. Knowing the lateral frame stiffness, $K$ (from Table 1) and using; $\delta=P / K$, the lateral displacement inducing buckling can be calculated. For example, the expected buckling displacement for test 3 is $4.44 \mathrm{~mm}$.

(e) The first yield displacement of the frame can be calculated in a similar manner to step $(d)$; however, the tension and compression forces in the bracing cannot be assumed to be 
equal as the yield capacity of the brace member is greater than its buckling capacity. The initial buckling capacity of the brace member reduces during subsequent load cycles as a result of residual out-of-plane deformation. The maximum compressive force in the bracing members therefore reduces in subsequent load cycles. In Goggins (2004), cyclic tests were performed on similar brace members $1.1 \mathrm{~m}$ long of section size $20 \times 20 \times 2 \cdot 0 \mathrm{~mm}$ SHS $\left(\bar{\lambda}=1 \cdot 6, r_{y}=\right.$ $0.727 \mathrm{~cm}), 50 \times 25 \times 2.5 \mathrm{~mm} \operatorname{RHS}\left(\bar{\lambda}=1 \cdot 2, r_{y}=0.994 \mathrm{~cm}\right)$ and $40 \times 40 \times 2.5 \mathrm{~mm} \mathrm{SHS}\left(\bar{\lambda}=0 \cdot 8, r_{y}=1.52 \mathrm{~cm}\right)$; where $r_{\mathrm{y}}$ is the radius of gyration about the weak axis. The average buckling capacity in subsequent load cycles of the $20 \times 20 \times 2.0 \mathrm{~mm}$ SHS (total of 22 cycles), $50 \times 25 \times$ $2.5 \mathrm{~mm}$ RHS (total of 14 cycles) and $40 \times 40 \times 2.5 \mathrm{~mm}$ SHS (total of 12 cycles) was approximately $52 \%, 58 \%$ and $67 \%$ that of the initial buckling capacity, respectively. These values were then used as a guide to estimate the reduced buckling capacity of the bracing members in this paper. Therefore, for the $30 \times 30 \times 3 \mathrm{~mm}$ SHS and $50 \times 30 \times 3 \mathrm{~mm}$ RHS sections used in these tests, the buckling capacity was reduced by an average estimated $50 \%$ and $60 \%$ for the $30 \times 30 \times 3 \mathrm{~mm}$ SHS $\left(\bar{\lambda}=1.68\right.$ and $\left.r_{y}=1.08 \mathrm{~cm}\right)$ and $50 \times 30 \times 3 \mathrm{~mm} \operatorname{RHS}\left(\bar{\lambda}=1.57\right.$ abd $\left.r_{y}=1.16 \mathrm{~cm}\right)$, respectively. For example, $F_{\mathrm{c}}=0 \cdot 5 N_{\mathrm{cr}}$ for $30 \times 30 \times 3 \mathrm{~mm}$ SHS and the lateral frame force corresponding to yield is

4. $P=\left(F_{\mathrm{c}}+F_{\mathrm{t}}\right) \cos \theta$

and as $F_{\mathrm{c}}=0 \cdot 5 N_{\mathrm{cr}}$

5. $P=\left(0 \cdot 5 N_{\mathrm{cr}}+F_{\mathrm{t}}\right) \cos \theta$

Using Equation 5, the lateral frame force is $P=69 \cdot 37 \mathrm{kN}$ for test 3 for the $30 \times 30 \times 3 \mathrm{~mm}$ SHS frame and $P=$ $101.4 \mathrm{kN}$ for test 6 for the $50 \times 30 \times 3 \mathrm{~mm}$ RHS frame. Knowing the lateral frame stiffness, $K$ (from Table 1) and using; $\delta=P / K$, for test 3 for example, the $30 \times 30 \times$ $3 \mathrm{~mm}$ SHS bracing tension yielding occurs at $7.38 \mathrm{~mm}$ corresponding to a brace tension force of $73.8 \mathrm{kN}$. Similarly, for test 6 the $50 \times 30 \times 3 \mathrm{~mm}$ RHS bracing tension yielding occurs at $9.45 \mathrm{~mm}$ corresponding to a brace tension force of $101.99 \mathrm{kN}$.

(f) Compare predicted displacements with displacement limits for buckling and yielding in order to infer the existence of structural damage.

\subsection{Reconstruction of displacement response from acceleration data}

Reliable reconstruction of displacement time history from noise-corrupted experimental acceleration signals requires careful design of an appropriate pre-processing procedure, in order to 'clean' the data from errors introduced by measurement noise and numerical manipulation. In this paper, the recorded signal is firstly filtered and baseline corrected to eliminate random high-frequency noise and low-frequency trends. The corrected acceleration is then integrated twice to retrieve the corresponding displacement signal. Subsequently, it is shown that a scaling gain can be conveniently applied to cater for numerical integration errors and further improve the agreement between the measured and the predicted displacement.

The first step in reconstructing the displacement signal is to deal with the issue of noise. Measurement noise in the acceleration signal results in inaccurate integration of undesired components of vibration, which are associated with intrinsic instrument error and non-linearities. In order to mitigate the effect of low-frequency drift and high-frequency measurement noise, a band-pass filter with appropriate cut-off frequencies is designed and applied to the acceleration signal. The frequency content of the recorded waveform is therefore analysed to select the cut-off frequencies of the filter.

Figure 3(b) shows the fast Fourier transform of the test frame acceleration recorded during the time history for test 3 (Figure 3(a)). As shown in Figure 3(b), the fundamental frequency of the structure was approximately $3 \mathrm{~Hz}$. A band-pass filter with cut-off frequencies of $0 \cdot 01 \mathrm{~Hz}$ and $25 \mathrm{~Hz}$ was applied to all acceleration signals. This filtering is beneficial for the reconstruction of the displacement time history from measured acceleration as it allows the useful signal to be separated from the noise and a linear frequency response to be obtained. Figure 4 shows the original and filtered acceleration signal for test 3. As expected, the band-pass filter is shown to smooth the signal and removes the higher frequencies.

In general, linear filtering alone is not sufficient to correct recorded acceleration signals that are integrated to give displacement. It is well known that direct integration of acceleration data may lead to unrealistic results for velocity and displacement, owing to initial baseline errors (Boore, 2001; Chiu, 1997; Trifunac, 1971; Wang, 1996). Chiu (1997) discusses different sources of errors that can be identified to explain the drifts in velocities and displacements computed by directly integrating raw acceleration records, including digitisation errors, low-frequency instrument noise, low-frequency background noise and mechanical or electrical hysteresis in a sensor. Baseline errors in particular have been shown to cause severe drifts if appropriate pre-processing schemes are not adopted (Yang et al., 2006). In fact, although the shifts in the baseline (zero level) are negligible in the acceleration signal, they may have a dramatic impact in computing the corresponding velocity and displacement waveforms. The double integration of the raw acceleration signal in test 3 is shown in Figure 5(a). A significant drift in the numerical displacement is clearly observed when compared to the measured frame displacement.

A comparison of different filtering techniques for dealing with baseline offsets in seismic accelerograms can be found in 


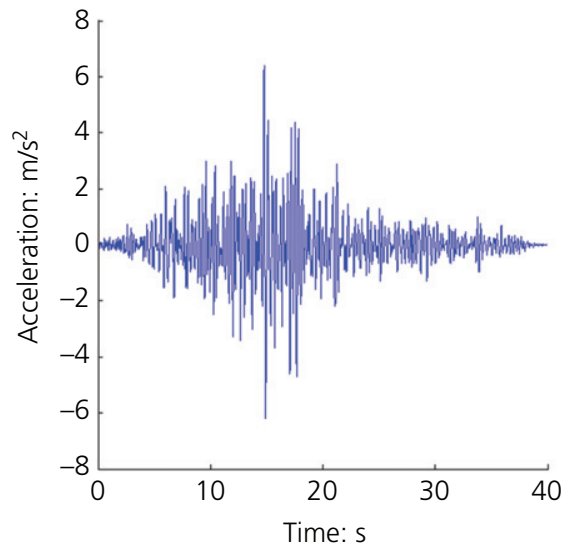

(a)

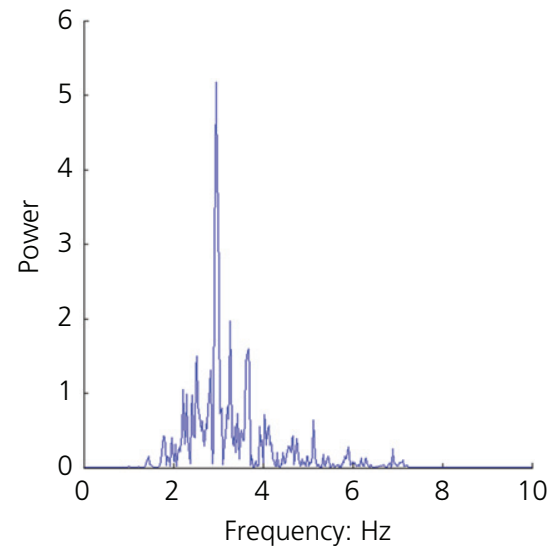

(b)

Figure 3. (a) Taiwan ground acceleration time history scaled to 2.0 PGA for test 3; and (b) fast Fourier transform of the measured acceleration time history for test 3

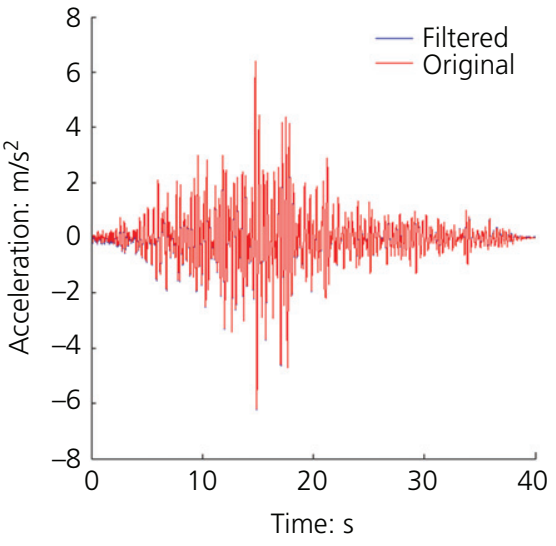

(a)

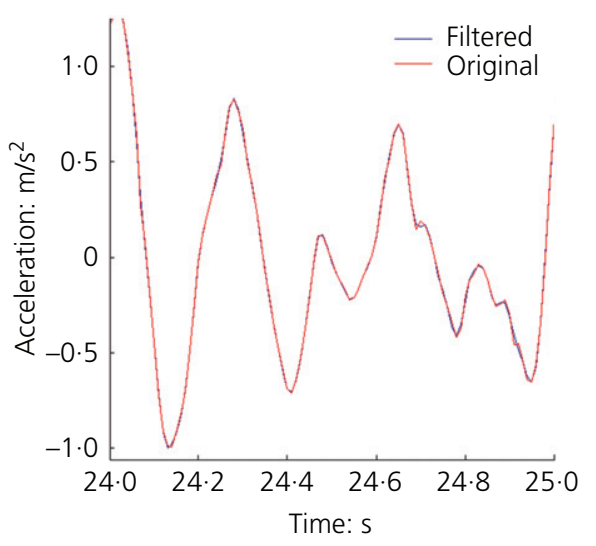

(b)

Figure 4. Original and filtered lateral in-plane acceleration signal with band-pass filter for test 3; (a) full signal and (b) close up

Crespellani et al. (2003). In this paper, a signal pre-processing scheme consisting of $(a)$ band-pass filtering and $(b)$ polynomial baseline correction of the acceleration and velocity time series is implemented in order to reconstruct the lateral displacement of the test frame. Correction of the baseline is performed using a polynomial least squares approach. The baseline component in the acceleration is fitted with a fifth-order polynomial and subtracted from the original waveform. The baseline-free acceleration is then integrated twice to obtain the corresponding displacement response. The double integration of the corrected acceleration signal in test 3 is shown in Figure 5(b). As is evident in the comparison of Figure 5(a) and (b), baseline correction represents an essential step in retrieving useful information from low-frequency acceleration signals.
For the purpose of illustration, the numerical (predicted) and the measured lateral in-plane frame displacement in test 3 are plotted in Figure 6(a). A high level of agreement between the predicted and the measured response is observed. For the six tests considered in this paper, the results of the application of the proposed methodology, denoted as filtered corrected integrated (FCI) scheme, are illustrated in Table 3. By comparing the measured and the FCI reconstructed displacement, a mean peak displacement error of $13.6 \%$ and a mean root mean square (RMS) displacement error of $13.5 \%$ are attained. The proposed scheme is therefore capable of providing a realistic quantitative prediction of the actual displacement response of the structure. Online implementation of the FCI scheme is also straightforward, as the data can be filtered during acquisition 


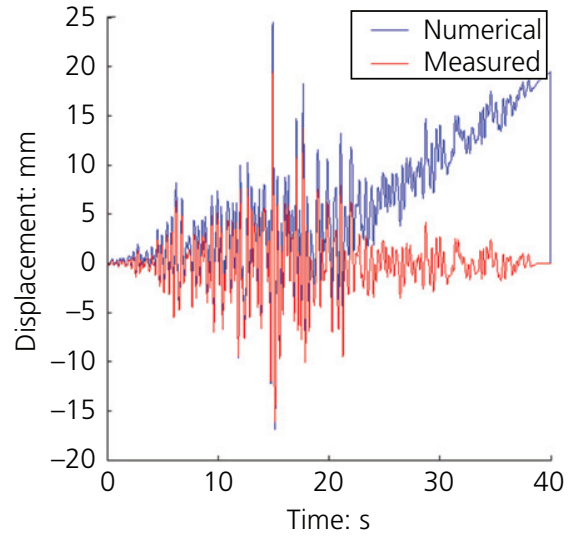

(a)

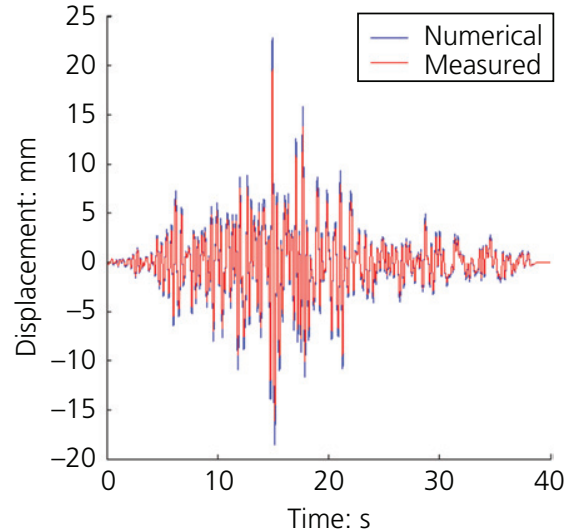

(b)

Figure 5. Direct double integration of lateral in-plane acceleration signal (numerical) compared to measured displacement for test 3; (a) without baseline correction and (b) with baseline correction

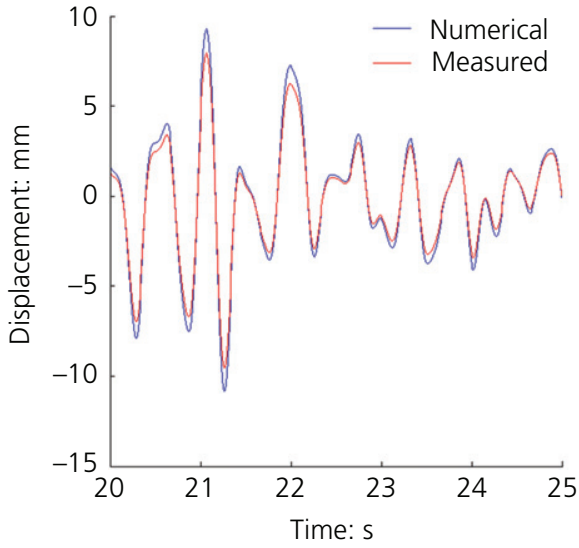

(a)

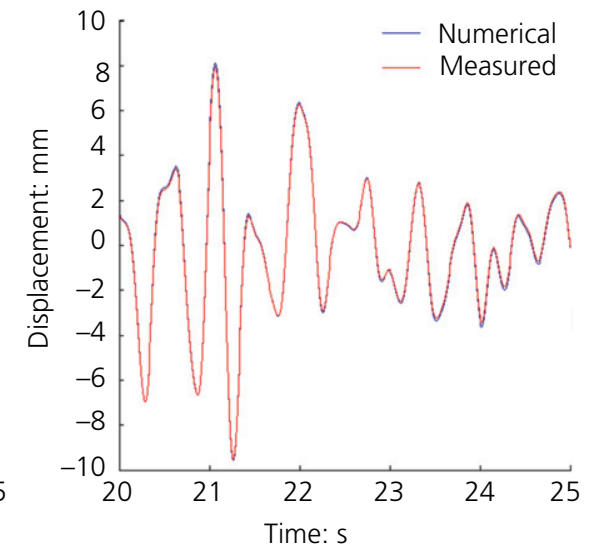

(b)

Figure 6. Lateral in-plane frame displacement plotted against time in test 3 from 20 to $25 \mathrm{~s}$; (a) without scaling gain ( $\mathrm{FCl}$ ); and (b) with scaling gain ( $\mathrm{FCIG}$ )

\begin{tabular}{|c|c|c|c|c|c|c|}
\hline $\begin{array}{l}\text { Test } \\
\text { no. }\end{array}$ & $\begin{array}{c}\text { Peak disp. } \\
\text { measured: mm }\end{array}$ & $\begin{array}{l}\text { Peak disp. } \\
\text { filtered: mm }\end{array}$ & $\begin{array}{l}\text { Peak disp. } \\
\text { Error: \% }\end{array}$ & $\begin{array}{c}\text { RMS disp. } \\
\text { measured: mm }\end{array}$ & $\begin{array}{l}\text { RMS disp. } \\
\text { filtered: mm }\end{array}$ & $\begin{array}{c}\text { RMS disp. } \\
\text { error: \% }\end{array}$ \\
\hline 1 & 3.92 & 4.44 & $13 \cdot 46$ & 0.59 & 0.68 & $15 \cdot 22$ \\
\hline 2 & 9.94 & 11.41 & $14 \cdot 77$ & 1.95 & $2 \cdot 25$ & $15 \cdot 20$ \\
\hline 3 & $19 \cdot 59$ & $22 \cdot 77$ & $16 \cdot 23$ & $2 \cdot 97$ & $3 \cdot 42$ & $15 \cdot 24$ \\
\hline 4 & 4.03 & $4 \cdot 51$ & $12 \cdot 03$ & $0 \cdot 78$ & $0 \cdot 88$ & $11 \cdot 58$ \\
\hline 5 & $10 \cdot 24$ & $11 \cdot 57$ & $12 \cdot 99$ & 1.93 & $2 \cdot 17$ & $12 \cdot 10$ \\
\hline \multirow[t]{3}{*}{6} & $20 \cdot 24$ & $22 \cdot 69$ & $12 \cdot 09$ & $3 \cdot 53$ & 3.95 & $11 \cdot 82$ \\
\hline & & Mean & $13 \cdot 6$ & & Mean & $13 \cdot 53$ \\
\hline & & COV & $2 \cdot 24$ & & COV & $2 \cdot 89$ \\
\hline
\end{tabular}

Table 3. Peak and RMS error between measured and FCI displacement 
and a windowed baseline correction operation can be easily performed. Online drift compensation methods based on wavelets (Hui et al., 2003) or Kalman filtering (Mneimneh et al., 2006; Wenzel et al., 2011), could be also applied.

Observation of the results in Table 3 indicates that a slight overestimation of the response is obtained using the FCI method for the cases considered. This observation suggests the presence of an error in the numerical integration of the acquired acceleration samples. In fact, the use of a finite time step for the numerical integration causes an approximation in the solution that depends on the size of the integration time step with respect to the time constants of the system. The time step during the tests was $0.01 \mathrm{~s}$ and a smaller time step would have resulted in improved accuracy of the numerical integration.

An additional parameter can therefore be introduced to mitigate the integration errors that affect the predicted displacements obtained with the FCI method. To this end, a constant scaling gain is applied to the FCI reconstructed displacements to improve further the agreement between the measured and the predicted numerically computed response. As shown in Figure 6(b), excellent improvement of the performances can be achieved by appropriately scaling the integrated displacement. The proposed method with application of the scaling gain is referred to as filtered corrected integrated gain (FCIG). The results illustrated in Table 4 show that for the cases considered in this paper a scaling gain of 0.88 provides excellent agreement between the measured and the predicted response, with peak displacement errors and RMS displacement errors in the order of $1 \%$. A high level of accuracy is therefore achieved in reconstructing the lateral displacement of the frame structure starting from the measured acceleration data.

\subsection{Verification of damage identification strategy}

The in-plane lateral displacement response of the CBF in test 3 subjected to a $2 \cdot 0$ scaled Taiwan excitation is shown in
Figure 7(a). Peak displacements of $16.3 \mathrm{~mm}$ and $-19.7 \mathrm{~mm}$ occur at approximately $15 \mathrm{~s}$ of the time history. The outof-plane displacement of the crossing point of the bracing members (LVDT B in Figure 1) can be seen in Figure 7(b) to peak at approximately $\pm 10 \mathrm{~mm}$ also after $15 \mathrm{~s}$ duration of the time history.

\subsubsection{Identification of brace member buckling}

Figure 8 (a) shows the first $7 \mathrm{~s}$ of the lateral in-plane displacement response of test 3 . The actuator load against in-plane lateral displacement of the cycles for the first $6.5 \mathrm{~s}$ is shown in Figure 8(b) (up to the point of unloading after point D in Figure 8(a)). The Euler buckling load is highlighted in Figure 8(b). The hysteresis plot of Figure 8(b) indicates buckling at displacements of $4.44 \mathrm{~mm}$ corresponding above a lateral in-plane (actuator) force of $41.74 \mathrm{kN}$. The negative displacement at point $\mathrm{D}$ of $-6.3 \mathrm{~mm}$ is slightly larger in amplitude than the displacement at point $\mathrm{C}$, hence the skewed appearance of the hysteresis plot. No buckling is observed in the hysteresis plot at points $\mathrm{A}$ and $\mathrm{B}$ as the structure remains linear. For cycles above $\pm 4.44 \mathrm{~mm}$ at points $\mathrm{C}$ and $\mathrm{D}$, slight non-linearity in the hysteresis plots can be seen in this compression and tension cycle. No yielding was observed in the strain gauge measurements (SG 4-11) during the first $7 \mathrm{~s}$ of test 3. Hence, the non-linearity in the hysteresis plot indicates buckling of the bracing members.

\subsubsection{Identification of brace member yielding}

Figure 9(a) shows the lateral in-plane displacement response of test 3 from 11 to $16 \mathrm{~s}$ of the time history. Figure 9(b) shows the hysteresis plot for the $\mathrm{E}$ to $\mathrm{F}$ displacement cycle occurring at approximately $12 \mathrm{~s}$. The yield displacement was calculated at $7 \cdot 38 \mathrm{~mm}$. Point E corresponds to a displacement of $9.51 \mathrm{~mm}$ and is above the predicted yield displacement as can be seen in Figure 9(b). Point F corresponds to a displacement of $-7.54 \mathrm{~mm}$ and is shown just to reach yielding as can be seen in Figure 9(b). During the positive displacement cycle yielding can be seen to occur as the hysteresis plot becomes non-linear.

\begin{tabular}{|c|c|c|c|c|c|c|}
\hline $\begin{array}{l}\text { Test } \\
\text { no. }\end{array}$ & $\begin{array}{c}\text { Peak disp. } \\
\text { measured: mm }\end{array}$ & $\begin{array}{l}\text { Peak disp. } \\
\text { filtered: mm }\end{array}$ & $\begin{array}{l}\text { Peak disp. } \\
\text { error: } \%\end{array}$ & $\begin{array}{c}\text { RMS disp. } \\
\text { measured: mm }\end{array}$ & $\begin{array}{l}\text { RMS disp. } \\
\text { filtered: mm }\end{array}$ & $\begin{array}{c}\text { RMS disp. } \\
\text { error: \% }\end{array}$ \\
\hline 1 & 3.92 & $3 \cdot 91$ & 0.15 & 0.59 & 0.60 & $1 \cdot 39$ \\
\hline 2 & $9 \cdot 94$ & $10 \cdot 04$ & 1.00 & 1.95 & 1.98 & $1 \cdot 38$ \\
\hline 3 & $19 \cdot 59$ & $20 \cdot 04$ & $2 \cdot 28$ & 2.97 & 3.01 & $1 \cdot 41$ \\
\hline 4 & 4.03 & 3.97 & $1 \cdot 40$ & 0.78 & 0.77 & $1 \cdot 80$ \\
\hline 5 & $10 \cdot 24$ & $10 \cdot 18$ & 0.56 & 1.93 & 1.90 & $1 \cdot 34$ \\
\hline \multirow[t]{3}{*}{6} & $20 \cdot 24$ & 19.96 & $1 \cdot 35$ & $3 \cdot 53$ & $3 \cdot 48$ & $1 \cdot 59$ \\
\hline & & Mean & $1 \cdot 12$ & & Mean & 1.49 \\
\hline & & COV & 0.46 & & COV & 0.03 \\
\hline
\end{tabular}

Table 4. Peak and RMS error between measured and FCIG displacement 


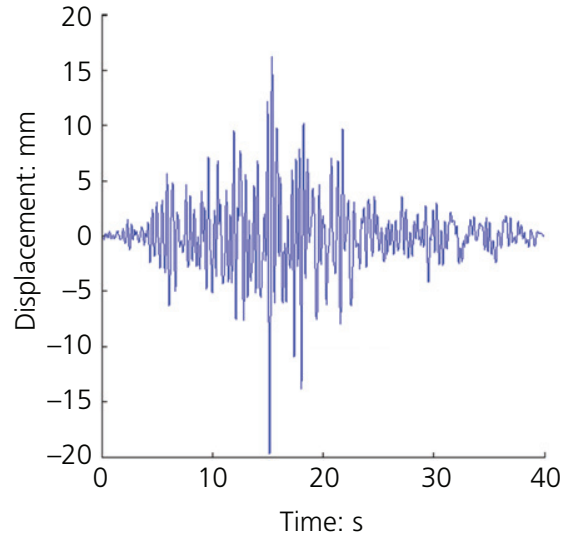

(a)

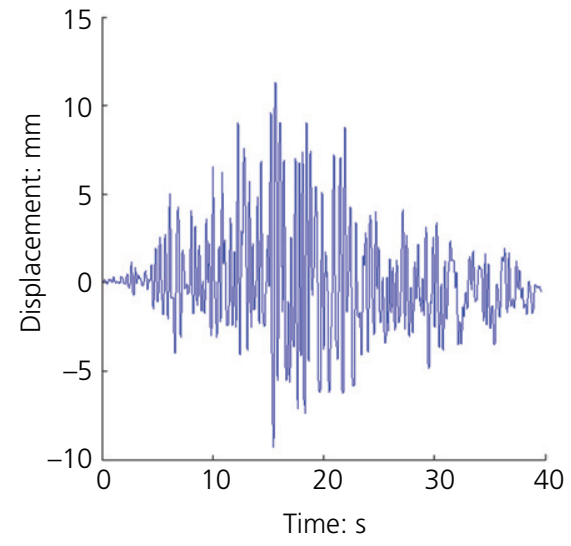

(b)

Figure 7. (a) In-plane lateral displacement response of test 3 frame at LVDT A (refer to Figure 1); and (b) out-of-plane displacement of bracing in test 3 at LVDT B (refer to Figure 1)

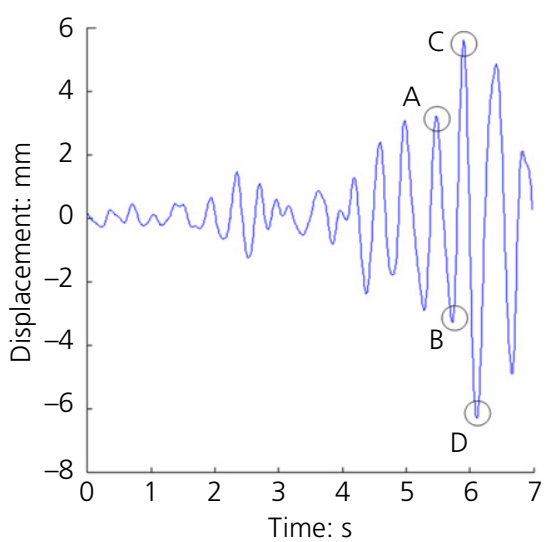

(a)

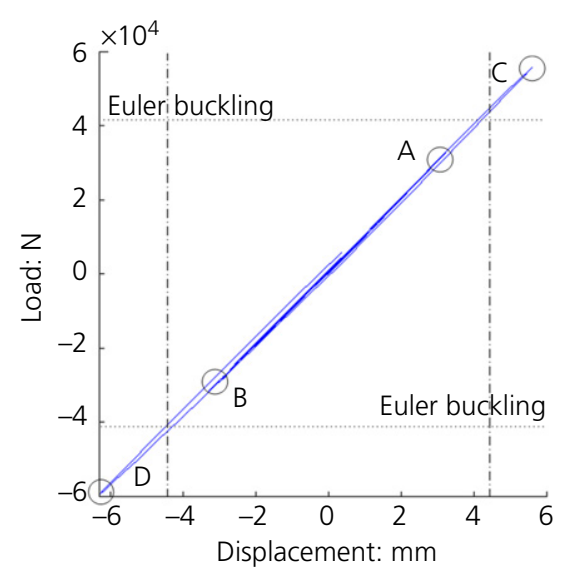

(b)

Figure 8. (a) Lateral in-plane displacement plotted against time for test 3 from 0 to $7 \mathrm{~s}$; and (b) lateral in-plane load (actuator) plotted against displacement hysteresis plot for test 3 from 0 to $6.5 \mathrm{~s}$

The hysteresis plot straightens on load reversal and some non-linearity can then be seen towards the peak of the negative displacement cycle at point $\mathrm{E}$.

Strain results are shown for SG 4, 5, 8 and 9 in Figure 10 because these sections of the bracing members have a slightly larger effective length than the upper portion of the bracing (refer to Figure 1 for strain gauge locations). The effective length of the bracing between the column and central connection is greater than the effective length of the bracing from the central connection to the beam. First yielding was observed in the hysteresis plot for test 3 at approximately $12 \mathrm{~s}$ (see Figure 9). From Figure 10(a) and (b), it can be seen that the peak strain is close to yield at this point in time (points $G$ and $\mathrm{H}$ in Figure 10(a) and (b), respectively), however does not quite reach yield. The error between the calculated and measured strain at SG 9 is $8 \cdot 1 \%$ (point $\mathrm{H}$ in Figure 10(b)).

As can be seen from Figure 10(a) and (b), yielding occurs in the bracing member at approximately $15 \mathrm{~s}$ in all strain gauges. Tension yielding was calculated to occur at a lateral inplane displacement of $7.38 \mathrm{~mm}$ and should have been observed at point $\mathrm{G}$ in Figure 10(a) and point $\mathrm{H}$ in Figure 10(b) corresponding to point $\mathrm{E}$ in Figure 9(a). The strain data in Figure 10 demonstrate the accuracy of the lateral displacement at almost predicting first yield in the bracing. As can be seen in Figure 10(a) and (b), the large amplitude displacement cycles at $15-16 \mathrm{~s}$ result in considerable permanent damage in the bracing as the permanent strain remains above yield in all strain gauges. 


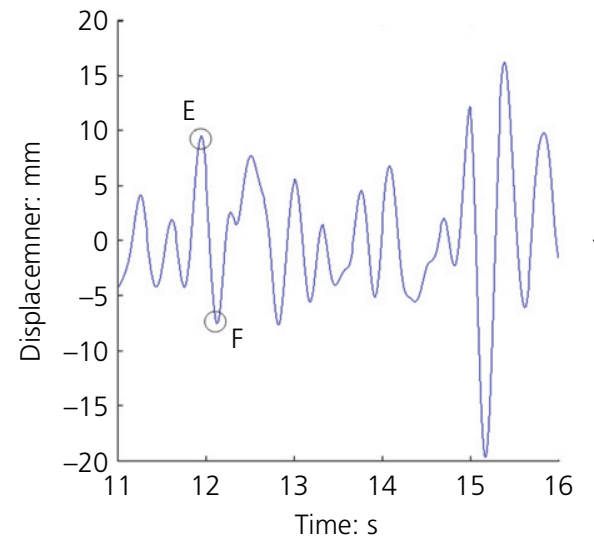

(a)

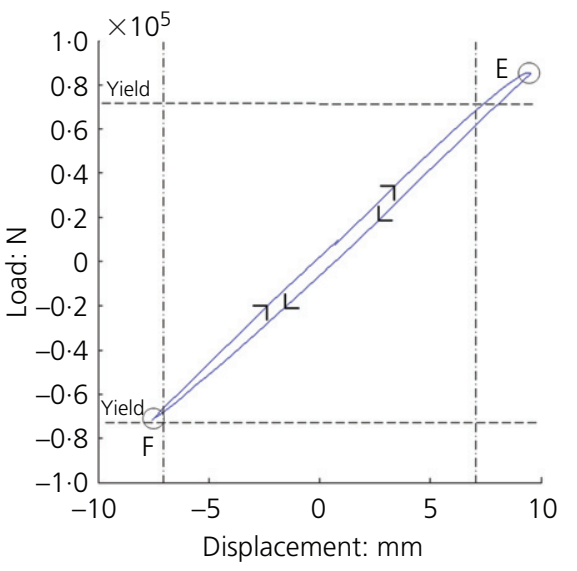

(b)

Figure 9. (a) Lateral in-plane displacement plotted against time for test 3 from 11-16 s; and (b) lateral in-plane load (actuator) plotted against displacement hysteresis plot for first yield cycle in test 3 at approximately $12 \mathrm{~s}$

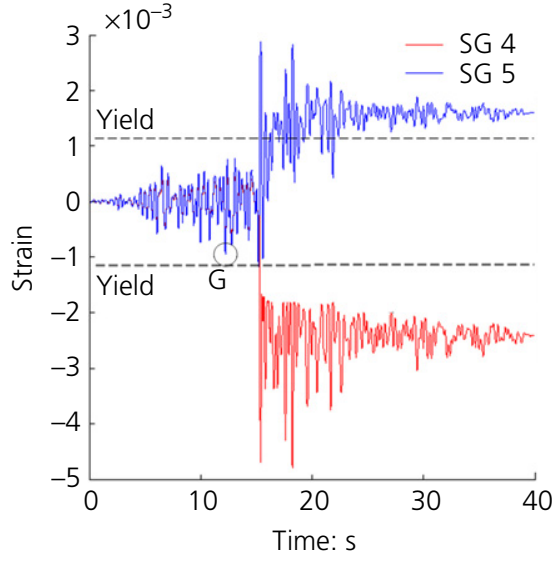

(a)

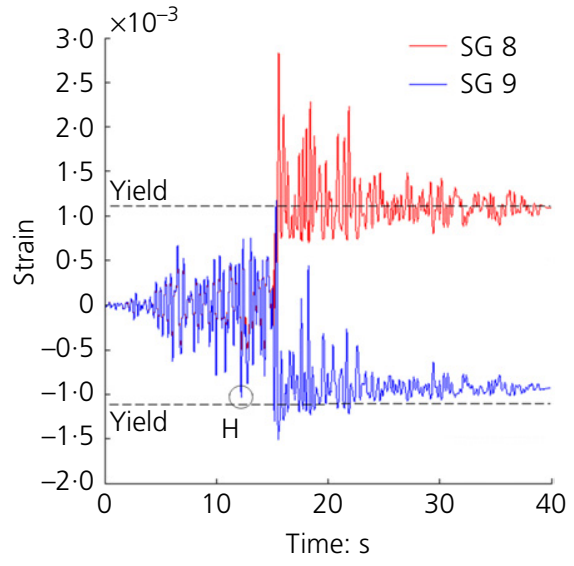

(b)

Figure 10. Strain plotted against time for test 3 for: (a) strain gauges 4 and 5; and (b) strain gauges 8 and 9

The damage in the bracing at the end of test 3 can be seen in Figure 11(b). A comparison of the undamaged CBF structure before test 1 can be seen in Figure 11(a). Permanent in and out-of-plane buckling is evident in Figure 11(b) after test 3.

The qualitative and quantitative summary of the results of all six tests is shown in Table 5. Qualitatively, the first visual observation of buckling during the tests was noted during each test and coincided with the predicted buckling displacement. Quantitatively, the predicted yield displacement is compared to strain gauge data and shown on average to predict first yield with an error of $2.9 \%$ as can be seen in Table 5. No error was observed in test 5 or test 6 as the measured yield strain coincided with the expected yield displacement.

\section{Conclusion}

This paper has presented a vibration-based seismic damage detection strategy for a single-storey steel CBF structure. A band-pass filter was used to remove noise from the acceleration signal followed by baseline correction being applied to reduce the drift in velocity and displacement during numerical integration. This pre-processing resulted in reliable numerical integration that predicts the displacement response accurately when compared to the measured lateral displacement of the 


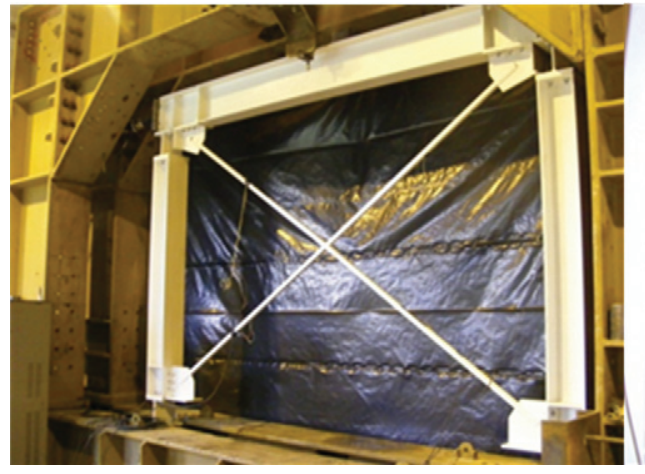

(a)

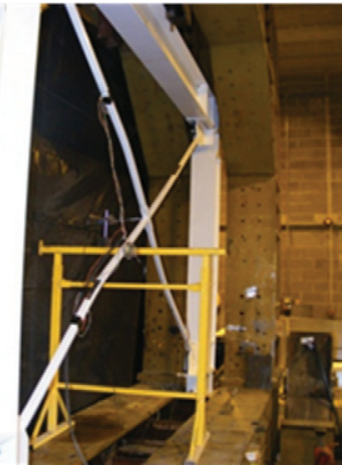

(b)

Figure 11. (a) Photograph of undamaged frame before test 1;

and (b) photograph of damaged bracing after completion of test 3

\begin{tabular}{|c|c|c|c|c|c|c|}
\hline $\begin{array}{l}\text { Test } \\
\text { no. }\end{array}$ & $\begin{array}{c}\text { Calc. buckle } \\
\text { disp.: mm }\end{array}$ & $\begin{array}{l}\text { Damage } \\
\text { observation }\end{array}$ & $\begin{array}{l}\text { Peak test } \\
\text { disp.: mm }\end{array}$ & $\begin{array}{l}\text { Calc. yield } \\
\text { disp.: } \mathrm{mm}\end{array}$ & $\begin{array}{l}\text { Meas. first } \\
\text { yield: mm }\end{array}$ & $\begin{array}{c}\text { First yield } \\
\text { error: \% }\end{array}$ \\
\hline 1 & $\pm 4 \cdot 25$ & None & -3.94 & \pm 7.07 & - & - \\
\hline 2 & $\pm 4 \cdot 24$ & Buckle (c. $11 \mathrm{~s})$ & $-10 \cdot 01$ & $\pm 7 \cdot 05$ & 10 (14s) & $3 \cdot 4$ \\
\hline 3 & $\pm 4 \cdot 44$ & Buckle (c. $6 \mathrm{~s})$ & $-19 \cdot 69$ & $\pm 7 \cdot 39$ & $9 \cdot 1(12 \mathrm{~s})$ & $8 \cdot 1$ \\
\hline 4 & $\pm 5 \cdot 82$ & None & 4.53 & \pm 8.89 & - & - \\
\hline 5 & \pm 5.96 & Buckle (c. $15 \mathrm{~s}$ ) & $-10 \cdot 28$ & $\pm 9 \cdot 09$ & $-10 \cdot 3(15 s)$ & 0.0 \\
\hline \multirow[t]{3}{*}{6} & $\pm 6 \cdot 19$ & Buckle (c. $6 \mathrm{~s})$ & $-19 \cdot 49$ & $\pm 9 \cdot 45$ & $11.9(14 \mathrm{~s})$ & 0.0 \\
\hline & & & & & Mean & $2 \cdot 9$ \\
\hline & & & & & COV & $11 \cdot 0$ \\
\hline
\end{tabular}

Table 5. Qualitative and quantitative summary of test results

CBF structure. A constant scaling gain can also be applied to the predicted displacement to improve the accuracy of the prediction compared to the measured displacement.

A novel damage detection methodology is presented that detects initiation of damage by calculating relative lateral inplane displacement threshold limits of buckling and yielding displacement of the CBF. The initial stiffness of the frame divided by the predicted threshold frame lateral force is used to identify if buckling and/or yielding have occurred in the bracing. Observation of the non-linearity in the hysteresis plot is used to verify the successful predictions of buckling in the bracing members. Strain data from seismic tests are used to verify the successful prediction of the tension yielding in the bracing members. The strategy was shown to predict buckling successfully in every test and predicted yielding with an average error of $2.9 \%$.

Importantly, the strategy presented here does not rely on detectable changes in response; rather it measures the level of interstorey drift to infer damage. The structural damage is not assumed through removal of bracing members, rather actual seismic loading on the structure induces structural damage. The damage detection strategy could also be easily extended to perform online to locate damage globally in a SHM scenario.

\section{Acknowledgements}

The testing in this paper was funded as part of an Irish Research Council for Science, Engineering and Technology scholarship. The authors would like to acknowledge the technical staff in the Structures Laboratory at Trinity College Dublin.

\section{REFERENCES}

Boore DM (2001) Effect of baseline corrections on displacements and response spectra for several recordings of the 1999 Chi-Chi Taiwan Earthquake. Bulletin of the Seismological Society of America 91(5): 1199-1211.

Carden PE and Fanning P (2004) Vibration based condition monitoring: a review. Structural Health Monitoring 3(4): 355-377.

CEN (Comité Européen de Normalisation) (2004) BS EN 1998-1:2004: Eurocode 8: Design of structures for 
earthquake resistance - Part 1: General rules, seismic actions and rules for buildings. BSI, London, UK.

CEN (2005) BS EN 1993-1-1:2005: Eurocode 3: Design of steel structures - Part 1-1: General rules and rules for buildings. BSI, London, UK.

Ching J and Beck JL (2004) Bayesian analysis of the phase II IASC-ASCE structural health monitoring experimental benchmark data. Journal of Engineering Mechanics 130(10): 1233-1244.

Chiu HC (1997) Stable baseline correction of digital strongmotion data. Bulletin of the Seismological Society of America, 87(4): 932-944.

Crespellani T, Facciorusso J, Madiai C and Vannucchi G (2003) Influence of uncorrected accelerogram processing techniques on Newmark's rigid block displacement evaluation. Soil Dynamics and Earthquake Engineering 23(6): 415-424.

Doebling SW, Farrar CR, Prime MB and Shevita DW (1996) Damage Identification and Health Monitoring of Structural and Mechanical Systems from Changes in their Vibration Characteristics: A Literature Review. Los Alamos National Laboratory Report, LA-13070-MS, Los Alamos, NM, USA.

Fan W and Qiao P (2011) Vibration-based damage identification methods: A review and comparative study. Journal of Structural Health Monitoring 10(1): 83-109.

Goggins J (2004) Earthquake Resistant Hollow and Filled Steel Braces. PhD Thesis, Department of Civil, Structural \& Environmental Engineering, Trinity College Dublin, Dublin, Ireland.

Hearn G and Testa RB (1989) Modal analysis for damage detection in structures. Journal of Structural Engineering 117(10): 3042-3063.

Hera A and Hou Z (2004) Application of wavelet approach for ASCE structural health monitoring benchmark studies. Journal of Engineering Mechanics 130(1): 96-104.

Hui D, Jun-Hua L and Zhong-ru S (2003) Drift reduction of gas sensor by wavelet and principal component analysis. Sensors and Actuators B: Chemical 96(1-2): 354-363.

IASC-ASCE (1999) SHM Task Group website; IASC-ASCE SHM Task Group website. See http://wusceel.cive.wustl. edu//asce.shm.

Johnson EA, Lam HF, Katafygiotis LS and Beck JL (2004) Phase I

IASC-ASCE structural health monitoring benchmark problem using simulated data. Journal of Engineering Mechanics 130(1): 3-15.

Kalman RE (1960) A new approach to linear filtering and prediction problems. Transactions of the ASME: Journal of Basic Engineering 82(Series D): 35-45.

Kharrazi MKH, Ventura CE, Brincker R and Dascotte E (2002). A study on damage detection using ouput-only modal data. Proceedings of IMAC 20: A Conference on Structural Dynamics, Beijing, China February 4-7, 2002, The Westin
Los Angeles Airport, Los Angeles, California. Society for Experimental Mechanics. pp. 1109-1125.

Koh CG, See LM and Balendra T (1992) Damage detection of buildings: numerical and experimental studies. Journal of Structural Engineering 121(8): 1155-1160.

Krishnan Nair K, Kiremidjian AS and Law KH (2006) Time series-based damage detection and localization algorithm with application to the ASCE benchmark structure. Journal of Sound and Vibration 291(1-2): 349-368.

McCrum DP and Broderick BM (2013a) Evaluation of a substructured soft real time hybrid test for performing seismic analysis of complex structural systems. Computers and Structures 129: 111-119.

McCrum DP and Broderick BM (2013b) An experimental and numerical investigation into the seismic performance of a multi-storey concentrically braced plan irregular structure. Bulletin of Earthquake Engineering 11(6): 2363-2385.

Mikami S, Beskhyroun S, Miyamori Y and Oshima T (2007) Application of a vibration-based damage detection algorithm on a benchmark structure. The 3rd International Conference On Structural Health Monitoring \& Intelligent Infrastructure: Structural Health Monitoring \& Intelligent Infrastructure. Ishmii-Int Soc Structural Health Monitoring Intelligent Infrastructure. U205-U212.

Mneimneh MA, Yaz EE, Johnson MT and Povinelli RJ (2006) An adaptive Kalman filter for removing baseline wandering in ECG signals. Proceedings of Computers in Cardiology 17-20(33): 253-256.

Morita K, Teshigawara M, Isoda H, Hamamoto T and Mita A (2001) Damage detection tests of five-storey steel frame with simulated damages. Proceedings of SPIE 4335, Advanced Nondestructive Evaluation for Structural and Biological Health Monitoring, Newport Beach, CA, USA, 106.

Sabatino S and Ervin EK (2012) Experimental damage diagnosis of a model three-storey spatial frame. Topics in Modal Analysis II, Volume 6, Conference Proceedings of the Society for Experimental Mechanics Series, Springer, New York, NY, USA, pp. 323-328.

Shing PB and Mahin SA (1984) Pseudodynamic test method for seismic performance evaluation: theory and implementation. Report UCB/EERC-84/01. Earthquake Engineering Research Center, University of California, Berkeley, USA.

Skolnik D and Wallace J (2010) Critical assessment of interstorey drift measurements. Journal of Structural Engineering 136(12): 1574-1584.

Sohn H, Farrar CR, Hemez FM et al. (2003) A review of structural health monitoring literature: 1996-2001. Los Alamos National Laboratory Report, LA-13976-MS, Los Alamos, NM, USA.

Trifunac MD (1971) Zero baseline correction of strong-motion accelerograms. Bulletin of the Seismological Society of America 61(5): 1201-1211. 
Wang LJ (1996) Processing of near-field earthquake accelerograms. Earthquake Engineering Research Laboratory, California Institute of Technology. Technical Report, CaltechEERL:1996.EERL-96-04, Pasadena, CA, USA.

Wenzel MJ, Mensah-Brown A, Josse F and Yaz EE (2011) Online drift compensation for chemical sensors using estimation theory. IEEE Sensors Journal 11(1): 225-232.

Wu JR and Li QS (2006) Structural parameter identification and damage detection for a steel structure using a two-stage finite element model updating method. Journal of Constructional Steel Research 62(5): 231-239.
Xiadong J, Jiaru Q and Longhe X (2007) Damage diagnosis of a two-storey spatial steel braced-frame model. Journal of Structural Control and Health Monitoring 14(8): 1083-1100.

Yao GC, Chang KC and Lee GC (1992) Damage diagnosis of steel frames using vibrational signature analysis. Journal of Engineering Mechanics 118(9): 1949-1961.

Yang J, Li JB and Lin G (2006) A simple approach to integration of acceleration data for dynamic soil-structure interaction analysis. Soil Dynamics and Earthquake Engineering 26(8): $725-734$.

\section{WHAT DO YOU THINK?}

To discuss this paper, please email up to 500 words to the editor at journals@ice.org.uk. Your contribution will be forwarded to the author(s) for a reply and, if considered appropriate by the editorial panel, will be published as discussion in a future issue of the journal.

Proceedings journals rely entirely on contributions sent in by civil engineering professionals, academics and students. Papers should be 2000-5000 words long (briefing papers should be 1000-2000 words long), with adequate illustrations and references. You can submit your paper online via www.icevirtuallibrary.com/content/journals, where you will also find detailed author guidelines. 